\title{
On the Flexural-Torsional Vibration and Stability of Beams Subjected to Axial Load and End Moment
}

\author{
M. Tahmaseb Towliat Kashani, Supun Jayasinghe, and Seyed M. Hashemi \\ Department of Aerospace Engineering, Ryerson University, Toronto, ON, Canada M5B 2K3 \\ Correspondence should be addressed to Seyed M. Hashemi; smhashem@ryerson.ca
}

Received 21 January 2014; Revised 19 June 2014; Accepted 19 June 2014; Published 13 October 2014

Academic Editor: Reza Jazar

Copyright ( 2014 M. Tahmaseb Towliat Kashani et al. This is an open access article distributed under the Creative Commons Attribution License, which permits unrestricted use, distribution, and reproduction in any medium, provided the original work is properly cited.

\begin{abstract}
The free vibration of beams, subjected to a constant axial load and end moment and various boundary conditions, is examined. Based on the Euler-Bernoulli bending and St. Venant torsion beam theories, the differential equations governing coupled flexural-torsional vibrations and stability of a uniform, slender, isotropic, homogeneous, and linearly elastic beam, undergoing linear harmonic vibration, are first reviewed. The existing formulations are then briefly discussed and a conventional finite element method (FEM) is developed. Exploiting the MATLAB-based code, the resulting linear Eigenvalue problem is then solved to determine the Eigensolutions (i.e., natural frequencies and modes) of illustrative examples, exhibiting geometric bending-torsion coupling. Various classical boundary conditions are considered and the FEM frequency results are validated against those obtained from a commercial software (ANSYS) and the data available in the literature. Tensile axial force is found to increase natural frequencies, indicating beam stiffening. However, when a force and an end moment are acting in combination, the moment reduces the stiffness of the beam and the stiffness of the beam is found to be more sensitive to the changes in the magnitude of the axial force compared to the moment. A buckling analysis of the beam is also carried out to determine the critical buckling end moment and axial compressive force.
\end{abstract}

\section{Introduction}

Beams are important and versatile structural elements as many civil, mechanical, and aerospace structures are commonly modeled as preloaded beams or beam assemblies [1]. In the past, many researchers have investigated the vibration and stability of various beam structures subjected to diverse loading and boundary conditions. As a result, the governing differential equations of motion for various beam configurations have been already developed. Therefore, from past literatures, it is known that the tensile and compressive axial loads affect the flexural stiffness of beams and increase or decrease the uncoupled bending frequencies and critical buckling loads of such elements. Apart from the above, various coupled vibrational behaviors of beam structures, caused by different geometric [2-10] and material couplings [1120], have also been thoroughly studied and their associated findings have been well established. The coupled vibrations and stability of axially loaded, or centrifugally stiffened, beam elements have also been investigated [21-31]. However, the literature on the effects of combined axial load and end moment and the couplings resulting from the end moment on the stability and vibration characteristics of beams are scarce [32-38].

Hashemi and Richard [2] used the frequency dependent dynamic finite element (DFE) method, a hybrid method developed in [3] that combines the accuracy of analytical methods to the versatility of numerical methods, to conduct a vibration analysis of beams that are geometrically coupled in bending and torsion. An exact method has been used to determine the flexural-torsional vibration characteristics of a uniform beam with single cross-sectional symmetry by Dokumaci [4]. The classical finite element method (FEM) was used by Mei [5] to study the coupled vibration of thin walled beams with an open section. This study included the effects of warping stiffness. The flexural-torsional vibration of a uniform beam was studied by Tanaka and Bercin [6] by determining the exact solution of the governing differential 
equations. An analytical dynamic stiffness matrix (DSM) solution was formulated by Banerjee [7] for coupled bendingtorsion beam elements. Banerjee et al. [8] also developed an exact DSM to investigate the vibration of an Euler-Bernoulli thin walled beam and exploited the Wittrick and Williams [9] root finding algorithm to extract the Eigensolutions. Once again, Banerjee and $\mathrm{Su}[10]$ used the DSM to conduct a free transverse and lateral vibration analysis of a beam coupled with torsion.

Hashemi and Roach [11] also formulated a DFE solution for the free vibration of an extension-torsion coupled composite beam. A quasi-exact DFE formulation for the free vibration analysis of a three layered sandwich beam, consisting of a thick, soft, low strength and density core and two-face layers made of high strength material, was developed by Hashemi and Adique [12]. Borneman and Hashemi [13] developed a DFE for the free vibration analysis of bending-torsion coupled laminated composite wing beams. Bannerjee and his coworkers have used the frequency-dependent DSM method for the vibration analysis of isotropic [14], sandwich [15-17], and composite [18] beams. Borneman et al. [19] also used the DSM method to investigate the vibrational characteristics of a doubly coupled (material and geometric) defective composite beam. Furthermore, a DSM formulation was presented by Hallauer and Liu [20] to determine the vibrational characteristics and generalized masses of an aircraft wing modelled as a series of three simple beams.

Hashemi and his coauthors [21] developed a DFE formulation to analyse the free vibration of centrifugally stiffened (rotating) beams. Furthermore, Hashemi and Richard [22] formed a DFE solution for the free vibration analysis of axially loaded bending-torsion coupled beams. An axially loaded isotropic Timoshenko beam coupled in bending and torsion was studied by Banerjee and Williams [23]. Leung [24] developed an exact DSM of a thin walled beam. Once again, an analytical solution was formulated by Banerjee and Fisher [25] to model a uniform, axially loaded, cantilevered beam with flexural-torsional coupling as a result of noncoincident shear and mass centers. The effects of warping have been neglected in this study. Jun et al. [26] examined the coupled flexural-torsional vibration of an axially loaded thin walled beam with monosymmetrical cross sections by including effects of warping. The effect of axial load has also been previously studied by Murthy and Neogy [27] for clamped and pinned boundary conditions, as well as by Gellert and Gluck [28] for cantilevered boundary conditions. Bokaian [29] determined the natural frequencies of a uniform single span beam subjected to a constant tensile axial load for various boundary conditions. The same author also investigated the vibrational characteristics of a uniform single span beam for ten different end conditions when a constant compressive axial load is applied [30]. Shaker [31] conducted a modal analysis to determine the effect of axial load on the mode shapes and natural frequencies of beams.

It has been established by Chen and Atsuta [39] that transverse bending and torsion is coupled by static end moments and that flexural-torsional buckling is comprised of this transverse flexure and axial torsion. Analytical investigations on the influence of axial loads and end moments on the vibration of beams have been previously reported by Joshi and Suryanarayan for a simply supported case [32] and other boundary conditions [33]. Joshi and Suryanarayan [34] also studied analytically the flexural-torsional instability of thin walled beams subjected to axial loads and end moments. The same authors examined the coupled bending-torsion vibration of a deep rectangular beam that is initially stressed as a result of the application of moments that vary along the span [35]. Pavlović and Kozić [36] developed a closed form analytical solution to investigate the effects of end moments on a simply supported thin walled beam. Furthermore, Pavlović et al. [37] also formulated the analytical solutions to study a simply supported thin walled beam subjected to the combined action of an axial force and end moment.

The reliability and accuracy of such modal analysis results depend on the method implemented. A variety of approaches for the analysis of these structures have been proposed and implemented in the past, including analytical, semianalytical, and numerical methods. Amongst these, the classical FEM method, where beam element matrices are evaluated from assumed fixed (namely, polynomial) shape functions, has been widely used by investigators. This practice results in approximate equations in the form of mass and static stiffness matrices. A deviation from the conventional FEM formulation would pay dividends if improved accuracy of results can be obtained by using shape functions other than polynomials. This is the case when the homogeneous solution of the pertinent differential equation is available for the development of each of the element matrices. For static analysis, the use of the homogeneous solution of the differential equation yields the exact stiffness matrix and load vector for a beam element [40]. The use of other alternative shape functions in dynamic FEM formulations has also been explored.

The dynamic stiffness matrix (DSM) method offers a better alternative particularly when higher frequencies and better accuracies of results are required. It relies on a single frequency-dependent matrix which has both mass and stiffness properties. The use of a DSM in vibration analysis is well established [14-18]. Obviously, the method gives more accurate results because it exploits the exact member theory. The matrix is obtained by directly solving the governing differential equation. Other methods have also been explored and reported which are more or less similar to those explained previously. Some of them were developed to treat a particular configuration and group of mechanical systems.

A thorough investigation of the existing conventional FEM and alternative DSM methods in beam vibrations has led to the development of the DFE approach [3]. DFE bridges the gap between the standard FEM and the exact DSM methods by advantageously exploiting the generality of FEM and the very precise frequency calculations provided by DSM approach. From this point of view, the method retains the physical aspect of analytical or semianalytical approaches and the power of a numerical method. It has been shown that DFE is an efficient tool for handling periodical structures or systems composed of several identical substructures [3]. 
All methods stated in the above-mentioned references have their inherent advantages and shortcomings. There exists a class of problems for which an exact solution can be obtained. Nevertheless, in most cases, finding a general exact solution for the normal modes and frequencies of the system would be cumbersome, if not impossible, and would involve complicated mathematical procedures. Thus, recourse would be made to one of approximate solutions such as the Rayleigh-Ritz method [41, 42] or Galerkin's method [40].

The conventional finite element method (FEM), which uses the Galerkin method of weighted residuals [40], is widely accepted and used for structural analysis. The FEM is adaptable to many complex systems, including those with material and geometric variations, for example, nonuniform geometry. However, it seems that a FEM-based thorough investigation of the geometrically coupled flexural-torsional vibration of beams, simultaneously subjected to both axial force and end moment, and the coupling effects caused by end moments have not been reported in the open literature. Therefore, in what follows, a classical FEM solution of the above problem is presented and the static buckling stability and the coupled free vibrations of preloaded thin (Euler-Bernoulli) beams, subjected to various classical end conditions (with ends free to warp), are investigated. The axial load and end moment are varied and their effects on the beam stiffness and natural frequencies are examined. It is worth noting that, in addition to the conventional beam stiffness and mass matrices $[38,40]$, the presented formulation is characterized by a geometric stiffness matrix, which includes uncoupled and coupled components. The uncoupled component, in turn, is formed by two parts, one associated with the flexure of axially loaded beams [38, 43, 44] and another relative to the torsion. However, to the best of authors' knowledge, the coupling geometric stiffness matrix resulting from the end moment has not been reported in the literature. The presented FEM formulation is applicable to the members composed of closed sections (e.g., rectangular or square hollow sections), where the torsional rigidity (GJ) is very large compared with the warping rigidity $(E \Gamma)$, with ends free to warp, that is, state of uniform torsion, where the twist rate is constant along the span. The presented FEM formulation, however, can also be extended to thin walled beams with open cross sections, where torsion-related warping effects cannot be neglected.

\section{Theory}

Consider a linearly elastic, homogeneous, isotropic beam subjected to an end moment, $M$, and an axial load, $P$, undergoing linear vibrations. Euler-Bernoulli bending and St. Venant torsion beam theories are used to derive the governing differential equations of motion and a classical finite element solution is developed. The end moments act about the $z$-axis (lagwise); however, bending in the $x$-y plane (lagwise) is not considered and bending occurs in the $x-z$ plane (flapwise). Thus, the end moments acting in the lagwise direction introduce torsion to the system and create

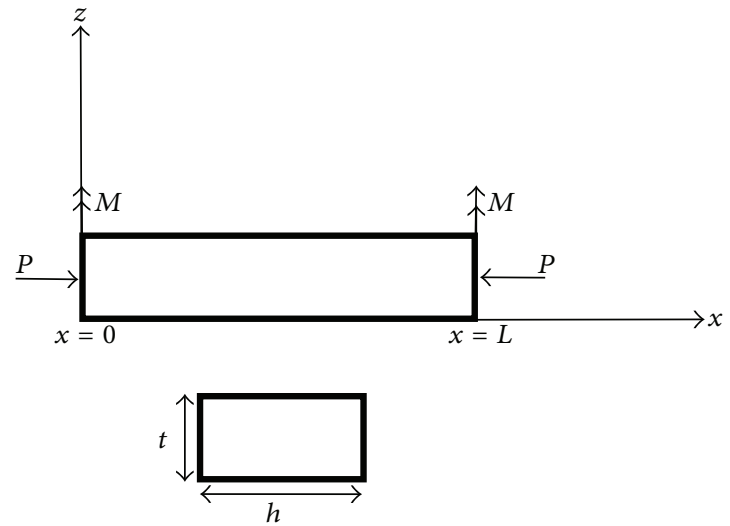

FIGURE 1: Beam with axial load and end moment applied at $x=0$ and $x=L$.

flexural-torsional coupling. Figure 1 illustrates the geometry of the studied system, where $L, h$, and $t$ stand for the beam's length, width, and height, respectively.

The two governing differential equations of the beam are as follows:

$$
\begin{aligned}
E I w^{\prime \prime \prime \prime}+P w^{\prime \prime}+M \theta^{\prime \prime}-\rho A \ddot{w} & =0, \\
G J \theta^{\prime \prime}+\frac{P I_{P}}{A} \theta^{\prime \prime}+M w^{\prime \prime}-\rho I_{P} \ddot{\theta} & =0,
\end{aligned}
$$

where $w$ stands for the transverse flexural displacement and $\theta$ represents the torsional displacement. The derivatives with respect to the length of the beam and time are denoted by a prime $(')$ and a dot (.), respectively. In (1) and (2), the applied moment and force are shown as $M$ and $P$, respectively. The cross-sectional area of the beam is denoted by $A$. The mass density is represented by $\rho$ and $I_{P}$ stands for the polar moment of inertia of the beam. The beam's torsional rigidity $(G J)$ is assumed to be very large compared with its warping rigidity $(E \Gamma)$, and ends are free to warp, that is, state of uniform torsion. As can be observed from (1) and (2), the system is coupled by the end moments, $M$.

In order to eliminate the time dependency in (1) and (2), simple harmonic vibration is considered and the following transformations are used to describe the transverse and torsional displacements:

$$
\begin{gathered}
w(x, t)=\widehat{W} \sin (\omega t), \\
\theta(x, t)=\widehat{\theta} \sin (\omega t),
\end{gathered}
$$

where $\omega$ is the circular frequency and $t$ is the time. $\widehat{W}$ and $\widehat{\theta}$ are the transverse and torsional displacement amplitudes, respectively. Upon substituting (3) and (4), (1) and (2) become

$$
\begin{aligned}
& E I \widehat{W}^{\prime \prime \prime \prime}+P \widehat{W}^{\prime \prime}+M_{z z} \widehat{\theta}^{\prime \prime}+\rho A \omega^{2} \widehat{W}=0, \\
& G J \widehat{\theta}^{\prime \prime}+P I_{P} \widehat{\theta}^{\prime \prime}+M_{z z} \widehat{W}^{\prime \prime}+\rho I_{P} A \omega^{2} \widehat{\theta}=0 .
\end{aligned}
$$


The Galerkin method of weighted residuals [40] is employed to develop the integral form of the above equations, where the "hat" signs have been dropped for the sake of simplicity:

$$
\begin{aligned}
& \bar{W}_{f}=\int_{0}^{L} \delta W\left(E I W^{\prime \prime \prime \prime}+P W^{\prime \prime}+M_{z z} \theta^{\prime \prime}+\rho A \omega^{2} W\right) d x=0, \\
& \bar{W}_{t}=\int_{0}^{L} \delta \theta\left(G J \theta^{\prime \prime}+\frac{P I_{P}}{A} \theta^{\prime \prime}+M_{z z} W^{\prime \prime}+\rho I_{P} \omega^{2} \theta\right) d x=0,
\end{aligned}
$$

where $\delta W$ and $\delta \theta$ (i.e., weighting functions) represent the transverse and torsional virtual displacements, respectively. Performing integration by parts on (7) and (8) leads to the weak integral form of the governing equations, written as

$$
\begin{aligned}
\bar{W}_{f}= & \int_{0}^{L}\left(E I W^{\prime \prime} \delta W^{\prime \prime}-P W^{\prime} \delta W^{\prime}+M \theta^{\prime} \delta W^{\prime}\right. \\
& \left.+\rho A \omega^{2} W \delta W\right) d x+\underline{\left[\left(E I W^{\prime \prime \prime}+P W^{\prime}+M \theta^{\prime}\right) \delta W\right]_{0}^{L}} \\
& -\left[\left(E I W^{\prime \prime}\right) \delta W\right]_{0}^{L}=0 \\
\bar{W}_{t}= & \int_{0}^{L}\left(G J \theta^{\prime} \delta \theta^{\prime}+\frac{P I_{P}}{A} \theta^{\prime} \delta \theta^{\prime}+M W^{\prime} \delta \theta^{\prime}-\rho I_{P} \omega^{2} \theta \delta \theta\right) d x \\
& -\left[\left(G J \theta^{\prime}+\frac{P I_{P}}{A} \theta^{\prime}+M W^{\prime}\right) \delta \theta\right]_{0}^{L}=0
\end{aligned}
$$

Expressions (9) and (10) also satisfy the principle of virtual work:

$$
\bar{W}=\bar{W}_{\mathrm{INT}}-\bar{W}_{\mathrm{EXT}}=0,
$$

where

$$
\bar{W}_{\mathrm{EXT}}=0 \text {, }
$$

and thus

$$
\bar{W}_{\mathrm{INT}}=\bar{W}_{f}+\bar{W}_{t}
$$

The total virtual work, internal virtual work, and external virtual work are denoted by $\bar{W}, \bar{W}_{\mathrm{INT}}$, and $\bar{W}_{\mathrm{EXT}}$, respectively. The resulting shear force $S(x)$, bending moment $M(x)$, and torsional torque $T(x)$, defined as

$$
\begin{gathered}
M(x)=-E I W^{\prime \prime}, \\
S(x)=E I W^{\prime \prime \prime}+M \theta^{\prime}+P W^{\prime}, \\
T(x)=G J \theta^{\prime}+\frac{P I_{P}}{A} \theta^{\prime}+M W^{\prime},
\end{gathered}
$$

are zero at the free end and the displacements are set to zero at the fixed boundaries. As a result, the bracketed boundary terms in expressions (9) and (10) vanish for all boundary conditions. The system is then discretized using elements

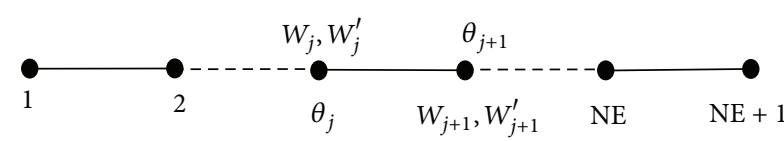

FIGURE 2: System discretized using elements with 3 degrees of freedom per node.

with 2 nodes and three DOF per node as shown in Figure 2 such that

$$
\bar{W}=\bar{W}_{\text {INT }}=\sum_{k=1}^{\text {No. of Elements }} \bar{W}^{k}=\sum_{k=1}^{\text {No. of Elements }} \bar{W}_{f}^{k}+\bar{W}_{t}^{k} .
$$

Nodal DOFs are lateral displacement $w$, rotation (i.e., slope) $w^{\prime}$, and torsional displacement $\theta$. The classical finite element formulation is developed using cubic Hermite type polynomial approximations for bending displacement (18) and linear approximations for torsional displacements (19) introduced in the weak integral form of the governing equations such that, for a two-node, three-degree-of-freedom per node element,

$$
\begin{aligned}
& w(x)=\left\langle\begin{array}{llll}
1 & x & x^{2} & x^{3}
\end{array}\right\rangle\left\{C_{1}\right\},
\end{aligned}
$$

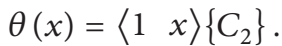

In (18) and (19) above $C_{1}$ and $C_{2}$ are columns vectors of unknown constant coefficients. The vectors of nodal displacement for bending and torsion are shown below:

$$
\begin{gathered}
\left\{W_{n}\right\}=\left\{\begin{array}{l}
W_{1} \\
W_{1}^{\prime} \\
W_{2} \\
W_{2}^{\prime}
\end{array}\right\}=\left[\begin{array}{llll}
1 & 0 & 0 & 0 \\
0 & 1 & 0 & 0 \\
1 & l & l^{2} & l^{3} \\
0 & 1 & 2 l & 3 l^{2}
\end{array}\right]\left\{C_{1}\right\}=\left[P_{n, w}\right]\left\{C_{1}\right\}, \\
\left\{\theta_{n}\right\}=\left\{\begin{array}{l}
\theta_{1} \\
\theta_{2}
\end{array}\right\}=\left[\begin{array}{ll}
1 & 0 \\
1 & l
\end{array}\right]\left\{C_{2}\right\}=\left[P_{n, t}\right]\left\{C_{2}\right\} .
\end{gathered}
$$

Thus,

$$
W(x)=\left\langle\begin{array}{llll}
1 & x & x^{2} & \left.x^{3}\right\rangle\left[P_{n, w}\right.
\end{array}\right]^{-1}\left\{W_{n}\right\}=\langle N(x)\rangle\left\{W_{n}\right\},
$$

$$
\theta(x)=\langle 1 \quad x\rangle\left[P_{n, t}\right]^{-1}\left\{\theta_{n}\right\}=\langle L(x)\rangle\left\{\theta_{n}\right\},
$$

where $\langle N(x)\rangle$ and $\langle L(x)\rangle$ are both row vectors comprising cubic and linear shape functions for bending and torsion, respectively. The cubic shape functions $N_{1}, N_{2}, N_{3}$, and $N_{4}$ are

$$
\begin{array}{cc}
N_{1}(x)=\frac{2 x^{3}}{l^{3}}-\frac{3 x^{2}}{l^{2}}+1, & N_{2}(x)=\frac{x^{3}}{l^{2}}-\frac{2 x^{2}}{l}+x, \\
N_{3}(x)=\frac{-2 x^{3}}{l^{3}}+\frac{3 x^{2}}{l^{2}}, & N_{4}(x)=\frac{x^{3}}{l^{2}}-\frac{x^{2}}{l} .
\end{array}
$$

The linear shape functions $L_{1}$ and $L_{2}$ are defined as

$$
L_{1}(x)=1-\frac{x}{l}, \quad L_{2}(x)=\frac{x}{l} .
$$

This discretizing process leads to the element stiffness and mass and coupling matrices which when assembled together 
within the FEM code written in MATLAB would result in the linear Eigenvalue problem shown in

$$
\begin{gathered}
\left\langle\delta W_{n}\right\rangle\left(K-\omega^{2} M\right)\left\{W_{n}\right\}=0, \\
\operatorname{det}\left(K-\omega^{2} M\right)=0,
\end{gathered}
$$

where $K$ stands for the global stiffness matrix, which is a collection of all the element stiffness matrices. The global mass matrix is symbolized by $M$.

Matrix (27a) shown below is the element mass matrix, $[m]^{k}$, and matrices (27b) through (27f) are the uncoupled, coupled, and geometric element stiffness matrices. When matrices (27b) through (27f) are assembled together, the final element stiffness matrix would result. This is shown as matrix (27g). Consider

$$
[m]^{k}=\left[\begin{array}{cccccc}
\frac{156 m l}{420} & \frac{22 m l^{2}}{420} & 0 & \frac{54 m l}{420} & \frac{-13 m l^{2}}{420} & 0 \\
& \frac{4 m l^{3}}{420} & 0 & \frac{13 m l^{2}}{420} & \frac{-3 m l^{3}}{420} & 0 \\
& & \frac{\rho I_{P} l}{3} & 0 & 0 & \frac{\rho I_{P} l}{6} \\
& & & \frac{156 m l}{420} & \frac{-22 m l^{2}}{420} & 0 \\
& & & \frac{4 m l^{3}}{420} & 0 \\
& & & & \frac{\rho I_{P} l}{3}
\end{array}\right]
$$

where $l$ stands for the element length and $m$ represents the element mass per unit length. The element uncoupled bending stiffness matrix, $\left[k_{B}\right]$, is shown below:

$$
\left[k_{B}\right]=\left[\begin{array}{cccc}
\frac{12 E I}{l^{3}} & \frac{6 E I}{l^{2}} & \frac{-12 E I}{l^{3}} & \frac{6 E I}{l^{2}} \\
& \frac{4 E I}{l} & \frac{-6 E I}{l^{2}} & \frac{2 E I}{l} \\
& \text { Sym. } & \frac{12 E I}{l^{3}} & \frac{-6 E I}{l^{2}} \\
& & & \frac{4 E I}{l}
\end{array}\right] .
$$

The final element stiffness matrix is modified due to the presence of the end moment and axial load which contributes the $[k]_{\text {geometric }}$ matrix, $[k]_{\text {torsion }}$ matrix, bendingtorsion coupling stiffness matrix, $\left[k_{B T}\right]_{c}$, and the torsionbending coupling stiffness matrix, $\left[k_{T B}\right]_{c}$. These are added to the bending stiffness matrix, $\left[k_{B}\right]$, above, to form the final element stiffness matrix, $[k]^{k}$. The geometric and torsion stiffness matrices contributed by the axial load $P$ are shown below:

$$
\begin{gathered}
{[k]_{\text {geometric }}=P\left[\begin{array}{rrrr}
\frac{6}{5 l} & \frac{1}{10} & \frac{-6}{5 l} & \frac{1}{10} \\
& \frac{2 l}{15} & \frac{-1}{10} & \frac{-l}{30} \\
\text { Sym. } & \frac{6}{5 l} & \frac{-1}{10} \\
& & \frac{2 l}{15}
\end{array}\right],} \\
{[k]_{\text {torsion }}=\left(\frac{G J}{l}+\frac{P I_{P}}{A l}\right)\left[\begin{array}{cc}
1 & -1 \\
-1 & 1
\end{array}\right] .}
\end{gathered}
$$

The bending-torsion and torsion-bending coupling stiffness matrices introduced by the end moment $M$ are as follows:

$$
\begin{gathered}
{\left[k_{B T}\right]_{c}=\frac{M}{l}\left[\begin{array}{cccc}
1 & 0 & -1 & 0 \\
-1 & 0 & 1 & 0
\end{array}\right],} \\
{\left[k_{T B}\right]_{c}=\frac{M}{l}\left[\begin{array}{cc}
1 & -1 \\
0 & 0 \\
-1 & 1 \\
0 & 0
\end{array}\right] .}
\end{gathered}
$$

Therefore, the final element stiffness matrix, which is a collection of the five submatrices, takes the following form:

$$
[k]^{k}=\left[\begin{array}{ccccccc}
\frac{12 E I}{l^{3}}-\frac{6 P}{5 l} & \frac{6 E I}{l^{2}}-\frac{P}{10} & \frac{M}{l} & \frac{-12 E I}{l^{3}}+\frac{6 P}{5 l} & \frac{6 E I}{l^{2}}-\frac{P}{10} & \frac{-M}{l} \\
& \frac{4 E I}{l}-\frac{2 P l}{15} & 0 & \frac{-6 E I}{l^{2}}+\frac{P}{10} & \frac{2 E I}{l}+\frac{P l}{30} & 0 \\
& & \frac{G J}{l}+\frac{P I_{P}}{A l} & \frac{-M}{l} & 0 & \frac{-G J}{l}-\frac{P I_{P}}{A l} \\
& \text { Sym. } & & \frac{12 E I}{l^{3}}-\frac{6 P}{5 l} & \frac{-6 E I}{l^{2}}+\frac{P}{10} & \frac{M}{l} \\
& & & \frac{4 E I}{l}-\frac{2 P l}{15} & 0 \\
& & & & \frac{G J}{l}+\frac{P I_{P}}{A l}
\end{array}\right] .
$$


TABLE 1: FEM results versus exact data for the first three natural frequencies at $P=0$ and $M=0$.

\begin{tabular}{|c|c|c|c|c|c|c|}
\hline \multirow{3}{*}{ Boundary condition } & \multicolumn{6}{|c|}{ Natural frequencies $(\mathrm{Hz})$ at $P=0$ and $M=0$} \\
\hline & \multicolumn{2}{|r|}{ Mode 1} & \multicolumn{2}{|c|}{ Mode 2} & \multicolumn{2}{|c|}{ Mode 3} \\
\hline & Exact [38] & FEM (40 elements) & Exact [38] & FEM (40 elements) & Exact [38] & FEM (40 elements) \\
\hline $\mathrm{C}-\mathrm{F}$ & 2.556 & 2.556 & 15.995 & 15.995 & 44.858 & 44.858 \\
\hline $\mathrm{C}-\mathrm{C}$ & 16.266 & 16.266 & 44.858 & 44.858 & 87.970 & 87.970 \\
\hline P-P & 7.175 & 7.175 & 28.718 & 28.718 & 64.633 & 64.633 \\
\hline $\mathrm{P}-\mathrm{C}$ & 11.209 & 11.209 & 36.351 & 36.351 & 75.611 & 75.611 \\
\hline
\end{tabular}

The solution to the linear Eigenvalue problem in (26) is achieved by determining the Eigenvalues and Eigenvectors using a FEM code developed in MATLAB. Various classical boundary conditions are also applied within the MATLAB code. Thus, the natural frequencies and mode shapes of the beam are evaluated.

It is worth noting that if the beam's warping rigidity $(E \Gamma)$ is large compared with its torsional rigidity $(G J)$, then torsion equation (2) changes to a 4 th-order differential equation, similar in form to the bending equation (1). While the above FEM formulation is developed for the state of uniform torsion, in that case, following the above-presented procedure and using cubic interpolation functions similar to (24) instead of linear ones (25), to express torsional displacements, the presented formulation can be extended to also include the warping effects. The development of such formulation, however, is beyond the scope of this paper.

\section{Numerical Results}

In this section, the validity and practical applicability of the presented FEM procedure are demonstrated through consideration of various examples. A generic beam made of structural steel, subjected to different combinations of axial load, end moment, and end conditions, is first investigated. In a second case study, the comparison is made between the FEM frequency results and limited experimental data available in the open literature.

At first, let us consider a beam made of structural steel $\left(E=200 \mathrm{GPa}\right.$ and $\left.\rho=7800 \mathrm{~kg} / \mathrm{m}^{3}\right)$, with a length of $8 \mathrm{~m}$, width of $0.4 \mathrm{~m}$, and depth of $0.2 \mathrm{~m}$. The first stage of the numerical tests was to validate the developed FEM code. Due to the lack of analytical results for the preloaded cases, the accuracy of the natural frequency values from the code was established by comparing with the analytical data for an unloaded beam. Table 1 includes the results for the first three natural frequencies for various boundary conditions (with ends free to warp) using the exact method [38] and a 40 -element FEM mesh. As it can be observed, the results produced by the exact and the FEM methods are identical and as such the FEM code generates accurate results.

The FEM mesh size was chosen based on a convergence test, as is presented in Figure 3. For this, a cantilever beam, subjected to $1.85 \mathrm{MN}$ of tensile force and $9.21 \mathrm{MN} \cdot \mathrm{m}$ of end moment, was used. With a focus on higher frequencies, the fifth mode in this case, the FEM convergence was

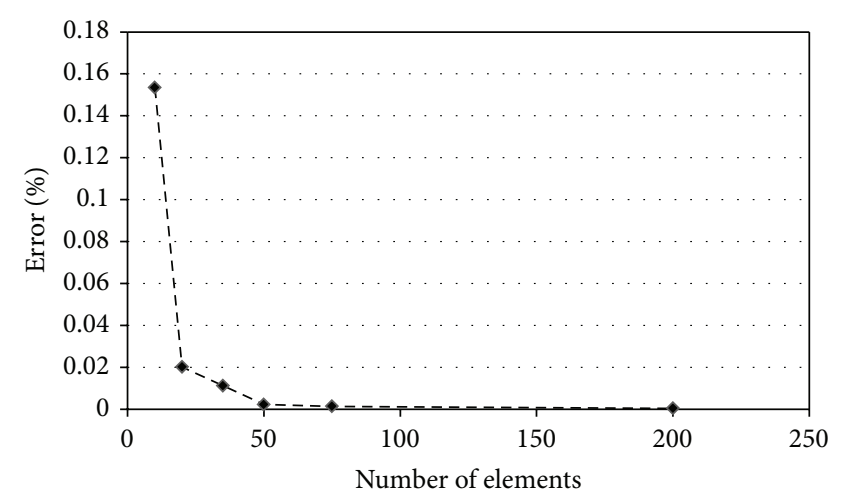

FIGURE 3: FEM convergence analysis; the fifth natural frequency of preloaded cantilevered beam.

investigated by increasing the numbers of elements from 10 to 1000 , as there were no analytical results available for similar cases. The fifth natural frequency was observed to remain at $88.243 \mathrm{~Hz}$, when 200 or more elements were used. Thus, for the given configuration, the $88.243 \mathrm{~Hz}$ value is taken as the exact reference result for the 5th natural frequency. However, since it is apparent that a 40 -element mesh results in an error less than 0.01 percent, such a mesh size was considered as reasonable for further studies. Furthermore, it is important to note that convergence of the results for the first four fundamental frequencies was also checked and it was observed that these results converged to the analytical result with an even smaller number of elements.

The accuracy of the results produced by the presented FEM method was also verified using a prestressed modal analysis conducted using ANSYS-14 commercial software, where SOLID-187 elements were used. The SOLID-187 element is a higher order, 3D, 10-node element, capable of 6 degrees of freedom ( 3 translations and 3 rotations) per node.

Tables 2, 3, 4, and 5 present the FEM fundamental frequencies for the beam subjected to different combinations of tensile force and end moment and various boundary conditions, cantilevered (C-F), clamped-clamped (C-C), pinned-pinned (P-P), and pinned-clamped (P-C), respectively. Table 2 also includes a comparison of the results from the developed FEM solution with those from the ANSYS software, which shows a maximum error of 1.3 percent at $P=0$ and $M=9.21 \mathrm{MN} \cdot \mathrm{m}$. These errors may be attributed to the fact that the ANSYS software incorporates the effects 
TABLE 2: Fundamental frequencies for cantilever beam subjected to force and end moment.

\begin{tabular}{lcccccc}
\hline C-F & & \multicolumn{2}{c}{$\begin{array}{c}\text { End moment } \\
6.14(\mathrm{MN} \cdot \mathrm{m})\end{array}$} & & \\
& & & \multicolumn{2}{c}{$\begin{array}{c}\text { Fundamental frequency }(\mathrm{Hz}) \\
9.21(\mathrm{MN} \cdot \mathrm{m})\end{array}$} \\
\hline Force $(\mathrm{MN})$ & ANSYS & FEM code 40 elements & ANSYS & FEM code 40 elements & ANSYS & FEM code 40 elements \\
\hline 0 & 2.555 & 2.556 & 2.241 & 2.234 & 1.749 & 1.727 \\
0.62 & 2.883 & 2.884 & 2.620 & 2.614 & 2.233 & 2.216 \\
1.23 & 3.168 & 3.169 & 2.939 & 2.934 & 2.614 & 2.600 \\
1.85 & 3.421 & 3.422 & 3.217 & 3.213 & 2.934 & 2.922 \\
\hline
\end{tabular}

TABLE 3: Fundamental frequencies for clamped-clamped boundary condition (C-C), when force and end moment are applied; a 40element FEM model is used.

\begin{tabular}{lccc}
\hline C-C & \multicolumn{3}{c}{ End moment (MN·m) } \\
& 0 & 6.14 & 9.21 \\
\hline Force $(\mathrm{MN})$ & \multicolumn{2}{c}{ FEM fundamental frequency $(\mathrm{Hz})$} \\
\hline 0 & 16.266 & 16.141 & 15.984 \\
0.62 & 16.413 & 16.290 & 16.134 \\
1.23 & 16.559 & 16.437 & 16.283 \\
1.85 & 16.703 & 16.582 & 16.430 \\
\hline
\end{tabular}

TABLE 4: Fundamental frequencies for pinned-pinned boundary condition (P-P), when force and end moment are applied; a 40element FEM model is used.

\begin{tabular}{lccc}
\hline P-P & \multicolumn{3}{c}{ End moment (MN·m) } \\
& 0 & 6.14 & 9.21 \\
\hline Force $(\mathrm{MN})$ & \multicolumn{2}{c}{ FEM fundamental frequency $(\mathrm{Hz})$} \\
\hline 0 & 7.175 & 6.947 & 6.651 \\
0.62 & 7.440 & 7.220 & 6.935 \\
1.23 & 7.695 & 7.483 & 7.208 \\
1.85 & 7.942 & 7.736 & 7.471 \\
\hline
\end{tabular}

TABLE 5: Fundamental frequencies for pinned-clamped boundary condition (P-C), when force and end moment are applied; a 40element FEM model is used.

\begin{tabular}{lccc}
\hline P-C & \multicolumn{3}{c}{ End moment (MN·m) } \\
& 0 & 6.14 & 9.21 \\
\hline Force $(\mathrm{MN})$ & \multicolumn{2}{c}{ FEM fundamental frequency $(\mathrm{Hz})$} \\
\hline 0 & 11.209 & 11.040 & 10.824 \\
0.62 & 11.408 & 11.242 & 11.031 \\
1.23 & 11.604 & 11.441 & 11.233 \\
1.85 & 11.796 & 11.636 & 11.432 \\
\hline
\end{tabular}

of shear deformation and rotary inertia into the calculations. The data tabulated in Tables 2 through 5 are also graphically presented in Figures 4, 5, 6, and 7. The critical buckling end moments and compressive forces were also determined for the cantilevered boundary condition and the results are shown in Tables 6 and 7, respectively. These tabulated data are also graphically presented in Figure 8. Finally, Figures 9 and 10 depict the bending and torsional components of the
TABLE 6: Critical buckling end moment versus compressive force; cantilevered boundary condition.

\begin{tabular}{lc}
\hline Force $(\mathrm{MN})$ & Buckling moment $(\mathrm{MN} \cdot \mathrm{m})$ \\
\hline-1.85 & 3.900 \\
-1.23 & 7.750 \\
-0.62 & 10.60 \\
0 & 12.28 \\
0.62 & 13.76 \\
1.23 & 15.57 \\
1.85 & 16.95 \\
\hline
\end{tabular}

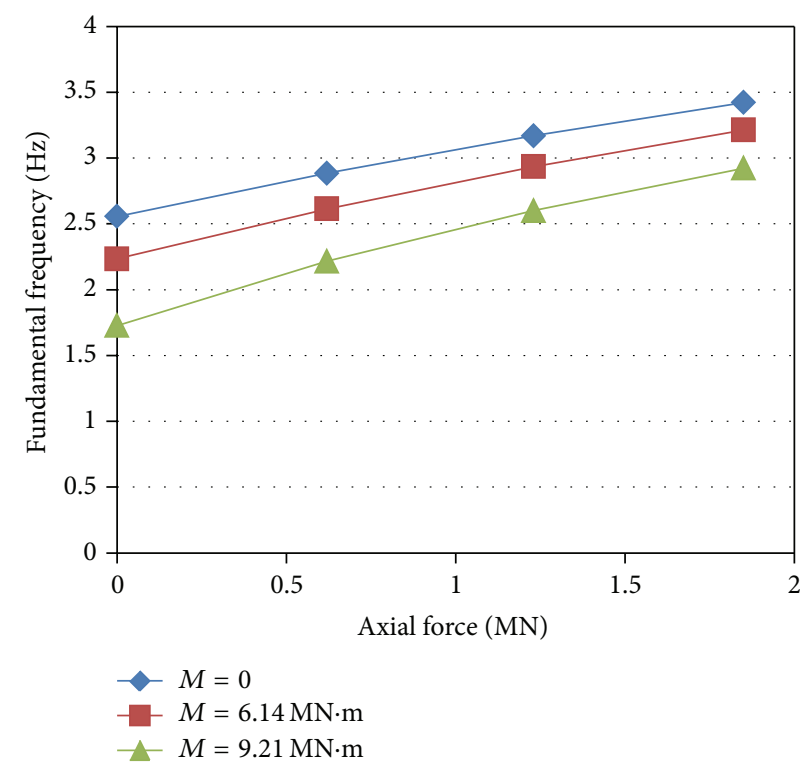

FIGURE 4: Variation of the fundamental frequency with tensile force and end moment; cantilevered (C-F) boundary condition.

first five natural modes, for the preloaded $(P=1.85 \mathrm{MN}$ and $M=9.21 \mathrm{MN} \cdot \mathrm{m}$ ) cantilevered beam.

Consider now the axially loaded, industrial aluminum beam $\left(E=70 \mathrm{GPa}\right.$ and $\left.\rho=2700 \mathrm{~kg} / \mathrm{m}^{3}\right)$, with a length of $1495 \mathrm{~mm}$, and rectangular cross section of $50 \mathrm{~mm}$ in width and $10 \mathrm{~m}$ min depth, as reported by Laux (2012) [45]. The first three natural frequencies of the beam, subjected to different axial loads, are calculated using the presented FEM formulation and are presented in Table 8, along with ANSYS results and experimental data reported in [45]. Different 


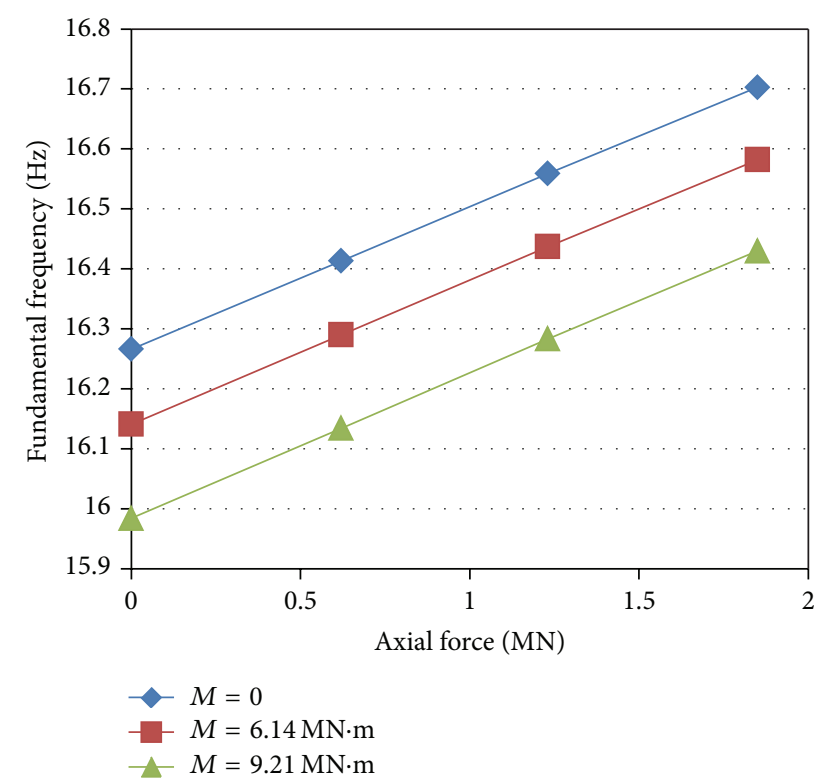

FIGURE 5: Variation of the fundamental frequency with tensile force and end moment; clamped-clamped (C-C) boundary condition.

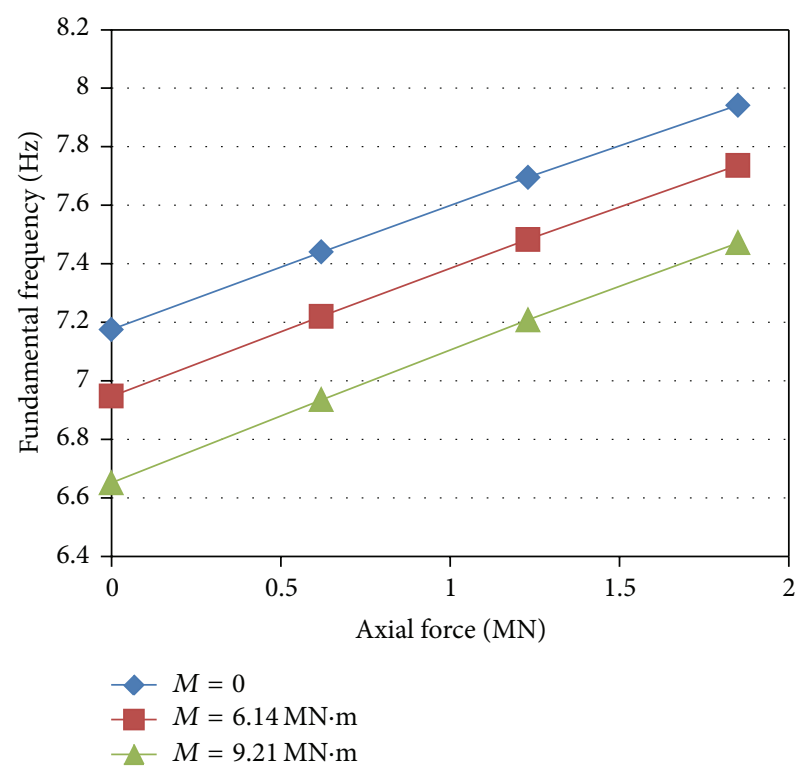

FIgURE 6: Variation of the fundamental frequency with tensile force and end moment; pinned-pinned (P-P) boundary condition.

mesh sizes are used and, as can be seen from the table, for the first and second natural frequencies, a 5-element course mesh and a 40-element fine mesh both lead to almost identical results. For the 3rd natural frequency, however, there is a slight difference of $0.5 \%$ between the results obtained from the two meshes. The FEM and ANSYS results are found to be in excellent agreement with the experimental data, with a maximum difference of less than $1 \%$. For the case in hand, however, there is no experimental buckling data available for comparison (refer to Table 9).

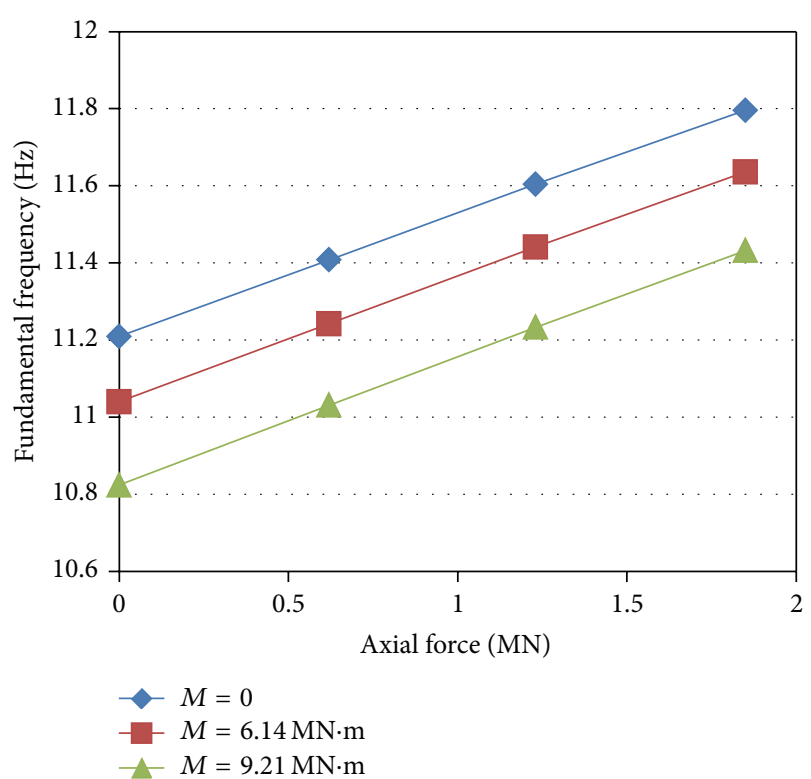

FIGURE 7: Variation of the fundamental frequency with tensile force and end moment; clamped-pinned (C-P) boundary condition.

TABLE 7: Critical buckling compressive force versus end moment; cantilevered boundary condition.

\begin{tabular}{lc}
\hline Moment $(\mathrm{MN} \cdot \mathrm{m})$ & Buckling force $(\mathrm{MN})$ \\
\hline 0 & -2.057 \\
3.07 & -1.900 \\
6.14 & -1.750 \\
9.21 & -0.900 \\
\hline
\end{tabular}

\section{Discussion and Conclusion}

The bending-torsion vibration and buckling of beams, subjected to axial load and end moment, were revisited. Neglecting the shear deformation, rotary inertia, and warping effects, the differential equations of motion, coupled by the end moment, were discussed. Exploiting the cubic and linear interpolation functions for bending and torsional displacements, respectively, together with the Galerkin-type weighted residual method, a finite element is developed. Frequency and stability analyses of two illustrative examples are carried out and the FEM results are compared with those obtained from ANSYS software and the data available in the literature. The presented FEM results showed excellent agreement with those obtained from ANSYS and experimental data. As expected, tensile axial load increases the natural frequencies of the beam, indicating an increase in the stiffness of the beam for all classical boundary conditions. When only the end moment is applied, the natural frequencies reduce for all boundary conditions, indicating a reduction in stiffness of the beam. If the end moment is held constant and the tensile load is increased, the natural frequencies increase indicating an increase in the beam stiffness. Conversely, if the tensile load is held constant and the end moment is increased, the beam stiffness reduces. A compressive axial load has 

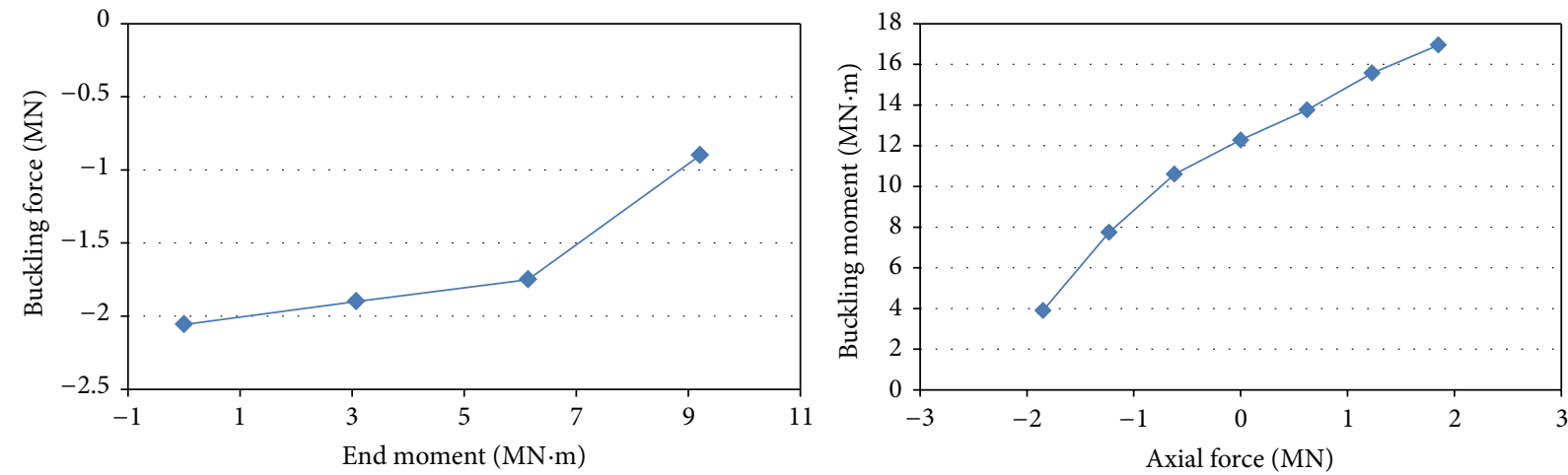

FIGURE 8: Variation of critical buckling compressive force with end moment.

TABLE 8: Comparison between the experimental and FEM natural frequencies versus axial load, for an aluminum fixed-fixed beam.

\begin{tabular}{|c|c|c|c|c|c|c|c|c|c|}
\hline \multirow{2}{*}{ Axial load $(\mathrm{N})$} & \multicolumn{3}{|c|}{ 1st nat. freq. (Hz) } & \multicolumn{3}{|c|}{ 2nd nat. freq. $(\mathrm{Hz})$} & \multicolumn{3}{|c|}{ 3rd nat. freq. $(\mathrm{Hz})$} \\
\hline & Exp. [45] & FEM $(5 / 40)$ & ANSYS (5/40) & Exp. [45] & FEM (5/40) & ANSYS (5/40) & Exp. [45] & FEM (5/40) & ANSYS $(5 / 40)$ \\
\hline 1962 & 36.0 & 36.1 & 36.1 & 93.1 & $94.0 / 94.0$ & $94.1 / 94.0$ & 177.0 & $180.3 / 179.1$ & $180.5 / 179.5$ \\
\hline 4022 & 40.0 & 40.1 & 40.1 & 98.9 & 99.8/99.9 & $99.8 / 99.8$ & 184.0 & $187.7 / 185.8$ & 187.7/186.6 \\
\hline 6671 & 44.5 & 44.6 & 44.6 & 106.6 & $107.4 / 107.4$ & $107.4 / 107.4$ & 193.9 & $196.5 / 195.5$ & $196.7 / 196.1$ \\
\hline 7750 & 46.4 & 46.5 & 46.5 & 109.6 & $110.5 / 110.5$ & $110.6 / 110.6$ & 197.6 & 200.9/199.7 & $201.2 / 200.0$ \\
\hline 9810 & 49.5 & 49.6 & 49.6 & 114.9 & $115.7 / 115.6$ & $115.6 / 115.5$ & 204.4 & $207.4 / 205.8$ & $207.4 / 206.2$ \\
\hline
\end{tabular}

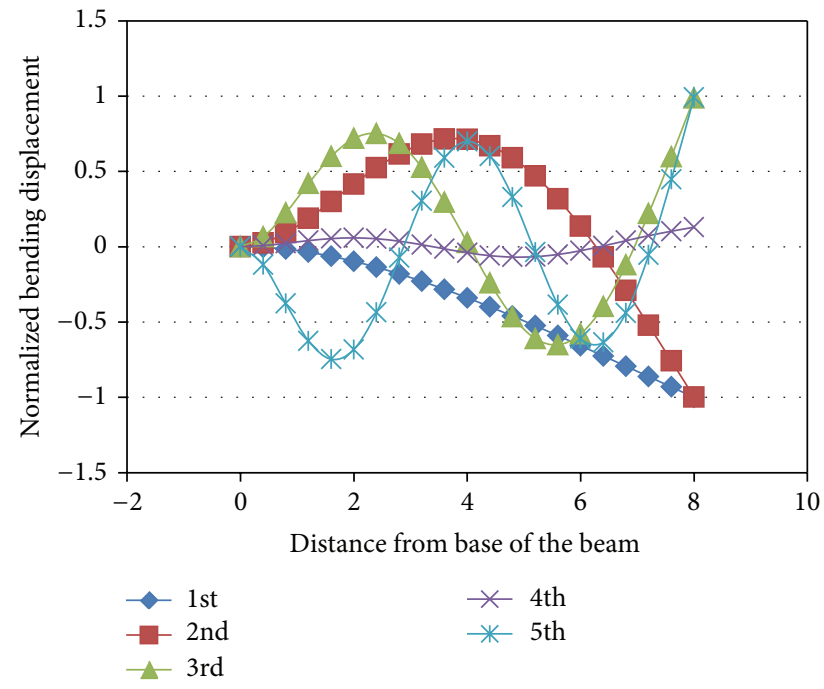

FIGURE 9: Bending component of the first five natural modes; preloaded cantilevered beam.

the opposite effect and the critical buckling moment reduces with a progressive increase in the compressive load applied. The coupled vibration of the beam, however, is found to be predominantly flexural in the first few natural frequencies (the first three, for the case studied here) and torsion becomes predominant in a higher natural frequency.

Finally, it is worth noting that the presented FEM is designed to account for the axial load, end moment, or combined effects automatically. In contrast, carrying out a similar analysis using the FEM-based software available

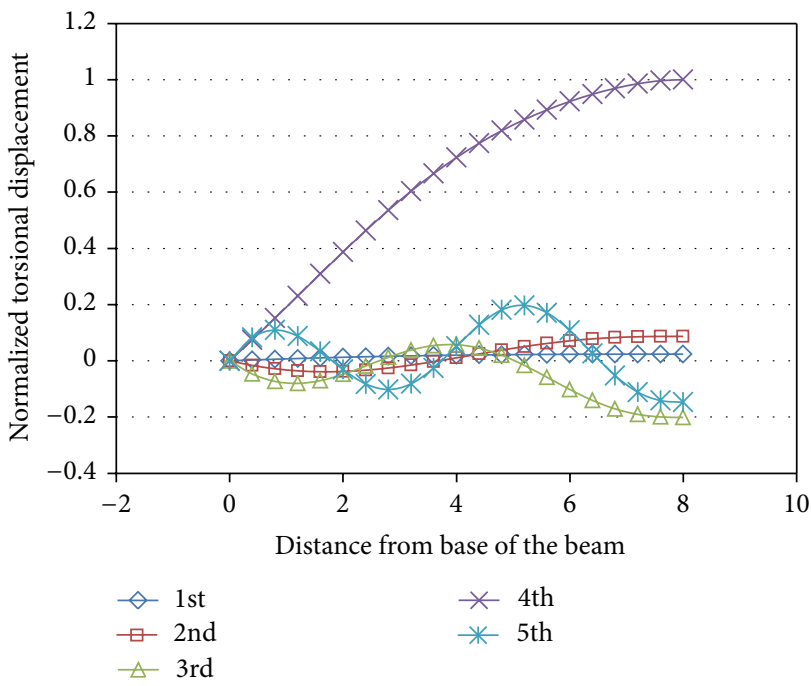

FIGURE 10: Torsional components of the first five natural modes; preloaded cantilevered beam.

(ANSYS, e.g.) needs special attention, as the preloads should be introduced in the model through a prestressed analysis. Furthermore, contrary to the analytical formulations, the presented FEM formulation can also be readily extended to the dynamic and stability analyses of (non-)uniform preloaded layered beams and beam structures, to include the warping effects, neglected in the present study, and to analyze beam-like structural components exhibiting other types of coupled behaviour, for example, geometric coupling 
TABLE 9: Critical buckling force versus end moment; fixed-fixed aluminum beam.

\begin{tabular}{lcc}
\hline \multirow{2}{*}{ Moment $(\mathrm{N} \cdot \mathrm{m})$} & \multicolumn{2}{c}{ Buckling Force (N) } \\
\hline 0 & FEM (5/40) & ANSYS (40) \\
50 & $708 / 707$ & 698 \\
100 & $669 / 669$ & 661 \\
150 & $551 / 551$ & 549 \\
205 & $354 / 348$ & 346 \\
\hline
\end{tabular}

noncoincident elastic and inertial axes, or material couplings in composite beams.

\section{Disclosure}

This paper presents the results of a recent research, conducted by the graduate students (M. Tahmaseb Towliat Kashani and Supun Jayasinghe), under the supervision of the third author (Seyed M. Hashemi). M. Tahmaseb Towliat Kashani and Supun Jayasinghe are coauthors. The authors also declare that the present paper in its present form has not been published, nor has it been submitted for publication, in any other journals.

\section{Conflict of Interests}

The authors declare that there is no conflict of interests regarding the publication of this paper.

\section{Acknowledgments}

This study was supported in part by NSERC Discovery Grant. Partial support was also provided by Ryerson University.

\section{References}

[1] S. Timoshenko, Vibration Problems in Engineering, Van Nostrand Reinhold, New York, NY, USA, 1964.

[2] S. M. Hashemi and M. J. Richard, "A Dynamic Finite Element (DFE) method for free vibrations of bending-torsion coupled beams," Aerospace Science and Technology, vol. 4, no. 1, pp. 41$55,2000$.

[3] S. M. Hashemi, Free vibrational analysis of rotating beam-like structures: a dynamic finite element approach [Ph.D. thesis], Department of Mechanical Engineering, Laval University, Quebec, Canada, 1998.

[4] E. Dokumaci, "An exact solution for coupled bending and torsion vibrations of uniform beams having single cross-sectional symmetry," Journal of Sound and Vibration, vol. 119, no. 3, pp. 443-449, 1987.

[5] C. Mei, "Coupled vibrations of thin-walled beams of open section using the finite element method," International Journal of Mechanical Sciences, vol. 12, no. 10, pp. 883-891, 1970.

[6] M. Tanaka and A. N. Bercin, "Free vibration solution for uniform beams of nonsymmetrical cross section using Mathematica," Computers and Structures, vol. 71, no. 1, pp. 1-8, 1999.
[7] J. R. Banerjee, "Coupled bending-torsional dynamic stiffness matrix for beam elements," International Journal for Numerical Methods in Engineering, vol. 28, no. 6, pp. 1283-1298, 1989.

[8] J. R. Banerjee, S. Guo, and W. P. Howson, "Exact dynamic stiffness matrix of a bending-torsion coupled beam including warping," Computers and Structures, vol. 59, no. 4, pp. 613-621, 1996.

[9] W. H. Wittrick and F. W. Williams, "A general algorithm for computing natural frequencies of elastic structures," The Quarterly Journal of Mechanics and Applied Mathematics, vol. 24, pp. 263-284, 1971.

[10] J. R. Banerjee and H. Su, "Free transverse and lateral vibration of beams with torsional coupling," Journal of Aerospace Engineering, vol. 19, no. 1, pp. 13-20, 2006.

[11] S. M. Hashemi and A. Roach, "A dynamic finite element for the free vibration analysis of extension-torsion coupled composite beams," Mathematics in Engineering, Science and Aerospace, vol. 1, no. 3, pp. 221-239, 2010.

[12] S. M. Hashemi and E. J. Adique, "A quasi-exact dynamic finite element for free vibration analysis of sandwich beams," Applied Composite Materials, vol. 17, no. 2, pp. 259-269, 2010.

[13] S. Borneman and S. M. Hashemi, "A dynamic finite element for the vibration analysis of tapered composite beams," in Proceeding of the 5th Canadian-International Composite Conference, Vancouver, Canada, 2005.

[14] J. R. Banerjee and F. W. Williams, "Free vibration of composite beams-an exact method using symbolic computation," Journal of Aircraft, vol. 32, no. 3, pp. 636-642, 1995.

[15] J. R. Banerjee, "Free vibration of sandwich beams using the dynamic stiffness method," Computers \& Structures, vol. 81, no. 18-19, pp. 1915-1922, 2003.

[16] J. R. Banerjee and A. J. Sobey, "Dynamic stiffness formulation and free vibration analysis of a three-layered sandwich beam," International Journal of Solids and Structures, vol. 42, no. 8, pp. 2181-2197, 2005.

[17] J. R. Banerjee, C. W. Cheung, R. Morishima, M. Perera, and J. Njuguna, "Free vibration of a three-layered sandwich beam using the dynamic stiffness method and experiment," International Journal of Solids and Structures, vol. 44, no. 22-23, pp. 7543-7563, 2007.

[18] J. R. Banerjee, H. Su, and C. Jayatunga, "A dynamic stiffness element for free vibration analysis of composite beams and its application to aircraft wings," Computers \& Structures, vol. 86, no. 6, pp. 573-579, 2008.

[19] S. R. Borneman, S. M. Hashemiand, and H. Alighanbari, "Vibration analysis of doubly coupled cracked composite beams: an exact dynamic stiffness matrix," International Review of Aerospace Engineering, vol. 1, no. 3, pp. 298-309, 2008.

[20] W. L. Hallauer and R. Y. L. Liu, "Beam bending-torsion dynamic stiffness method for calculation of exact vibration modes," Journal of Sound and Vibration, vol. 85, no. 1, pp. 105-113, 1982.

[21] S. M. Hashemi, M. J. Richard, and G. Dhatt, "A new Dynamic Finite Element (DFE) formulation for lateral free vibrations of Euler-Bernoulli spinning beams using trigonometric shape functions," Journal of Sound and Vibration, vol. 220, no. 4, pp. 601-624, 1999.

[22] S. M. Hashemi and M. J. Richard, "Free vibrational analysis of axially loaded bending-torsion coupled beams: a dynamic finite element," Computers and Structures, vol. 77, no. 6, pp. 711-724, 2000 . 
[23] J. R. Banerjee and F. W. Williams, "Coupled bending-torsional dynamic stiffness matrix of an axially loaded timoshenko beam element," International Journal of Solids and Structures, vol. 31, no. 6, pp. 749-762, 1994.

[24] A. Y. T. Leung, "Natural shape functions of a compressed Vlasov element," Thin-Walled Structures, vol. 11, no. 5, pp. 431-438, 1991.

[25] J. R. Banerjee and S. A. Fisher, "Coupled bending-torsional dynamic stiffness matrix for axially loaded beam elements," International Journal for Numerical Methods in Engineering, vol. 33, no. 4, pp. 739-751, 1992.

[26] L. Jun, S. Rongying, H. Hongxing, and J. Xianding, "Coupled bending and torsional vibration of axially loaded BernoulliEuler beams including warping effects," Applied Acoustics, vol. 65 , no. 2, pp. 153-170, 2004.

[27] M. Murthy and J. Neogy, "Determination of fundamental natural frequencies of axially loaded columns and frames," Journal of the Institution of Engineers (India) Civil Engineering Division, vol. 49, pp. 203-212, 1969.

[28] M. Gellert and J. Gluck, "The influence of axial load on eigen-frequencies of a vibrating lateral restraint cantilever," International Journal of Mechanical Sciences, vol. 14, no. 11, pp. 723-728, 1972.

[29] A. Bokaian, "Natural frequencies of beams under compressive axial loads," Journal of Sound and Vibration, vol. 126, no. 1, pp. 49-65, 1988.

[30] A. Bokaian, "Natural frequencies of beams under tensile axial loads," Journal of Sound and Vibration, vol. 142, no. 3, pp. 481498, 1990.

[31] F. J. Shaker, "Effect of axial load on mode shapes and frequencies of beams," NASA Technical Note TN D-8109, 1975.

[32] A. Joshi and S. Suryanarayan, "Coupled flexural-torsional vibration of beams in the presence of static axial loads and end moments," Journal of Sound and Vibration, vol. 92, no. 4, pp. 583-589, 1984.

[33] A. Joshi and S. Suryanarayan, "Unified analytical solution for various boundary conditions for the coupled flexural-torsional vibration of beams subjected to axial loads and end moments," Journal of Sound and Vibration, vol. 129, no. 2, pp. 313-326, 1989.

[34] A. Joshi and S. Suryanarayan, "A unified solution for various boundary conditions for the coupled flexural-torsional instability of closed thin-walled beam-columns," International Journal of Solids and Structures, vol. 20, no. 2, pp. 167-178, 1984.

[35] A. Joshi and S. Suryanarayan, "Iterative method for coupled flexural-torsional vibration of initially stressed beams," Journal of Sound and Vibration, vol. 146, no. 1, pp. 81-92, 1991.

[36] R. Pavlović and P. Kozić, "Almost sure stability of the thinwalled beam subjected to end moments," Theoretical and Applied Mechanics, vol. 30, no. 3, pp. 193-207, 2003.

[37] R. Pavlović, P. Kozić, P. Rajković, and I. Pavlović, "Dynamic stability of a thin-walled beam subjected to axial loads and end moments," Journal of Sound and Vibration, vol. 301, no. 3-5, pp. 690-700, 2007.

[38] J. S. Przemieniecki, Theory of Matrix Structural Analysis, McGraw-Hill, New York, NY, USA, 1968.

[39] W. F. Chen and T. Atsuta, Theory of Beam Columns Space Behaviour and Design Volume, McGraw-Hill, New York, NY, USA, 1977.

[40] K. J. Bathe, Finite Element Procedures, Prentice Hall, New York, NY, USA, 1996.

[41] L. Meirovitch, Analytical Methods in Vibrations, The MacMillan, 1967.
[42] L. Meirovitch, Computational Methods in Structural Dynamics, Sijthoff \& Noordhoff, 1980.

[43] F. Y. Chen, Matrix Analysis of Structural Dynamics: Applications and Earthquake Engineering, Marcel Decker, New York, NY, USA, 2001.

[44] J. S. Wu, Analytical and Numerical Methods for Vibration Analysis, John Wiley \& Sons, Singapore, 2013.

[45] S. Laux, Estimation of axial load in timber beams using resonance frequency analysis [M.S. thesis], Chalmers University of Technology, Gothenburg, Sweden, 2012. 

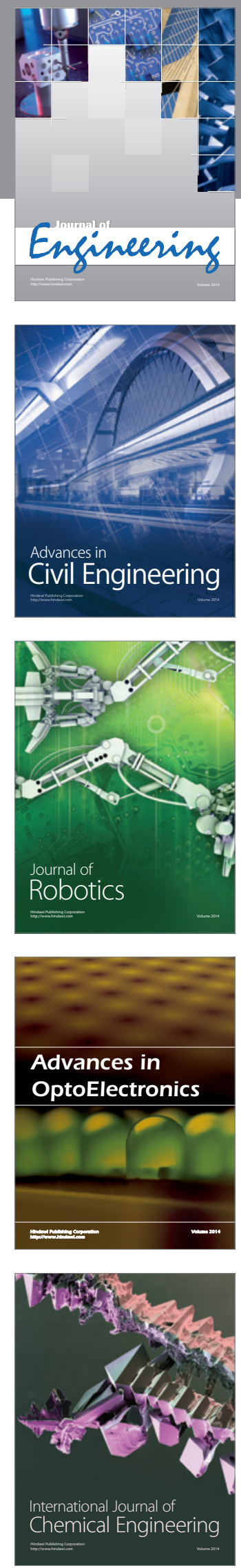

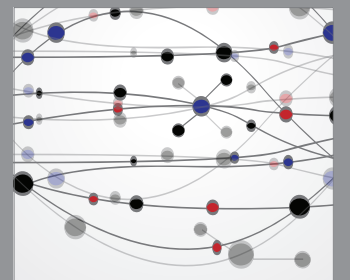

The Scientific World Journal
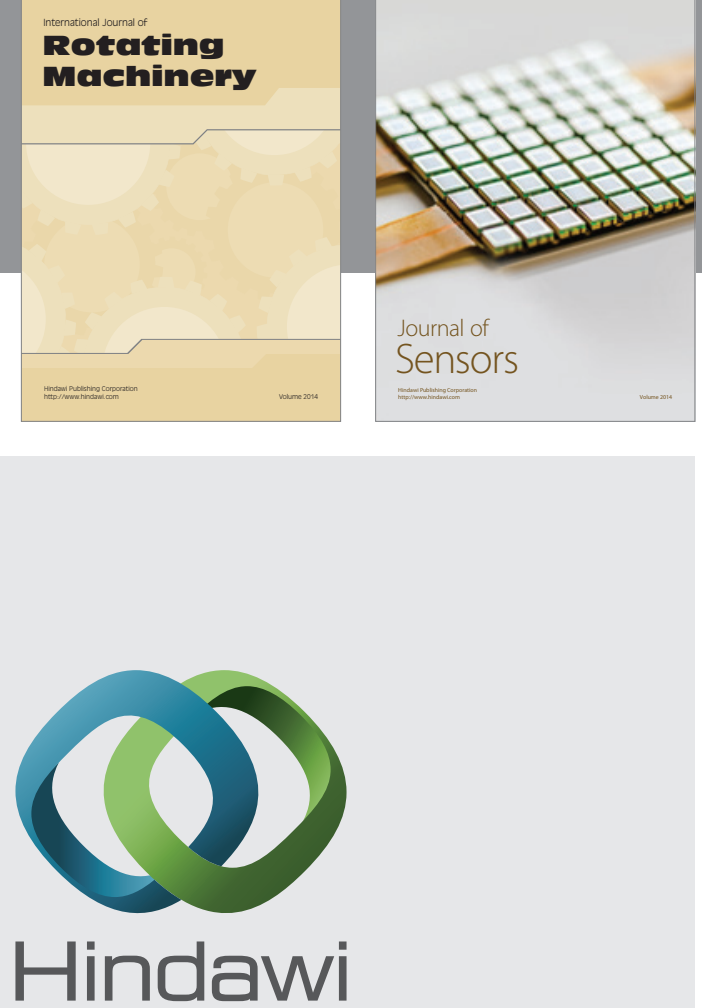

Submit your manuscripts at http://www.hindawi.com
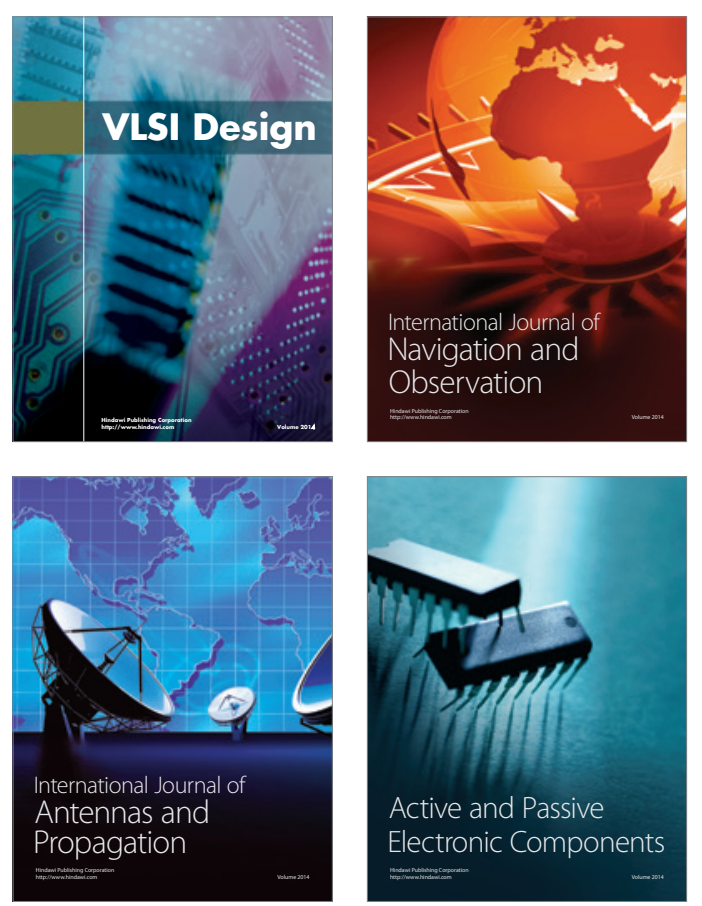
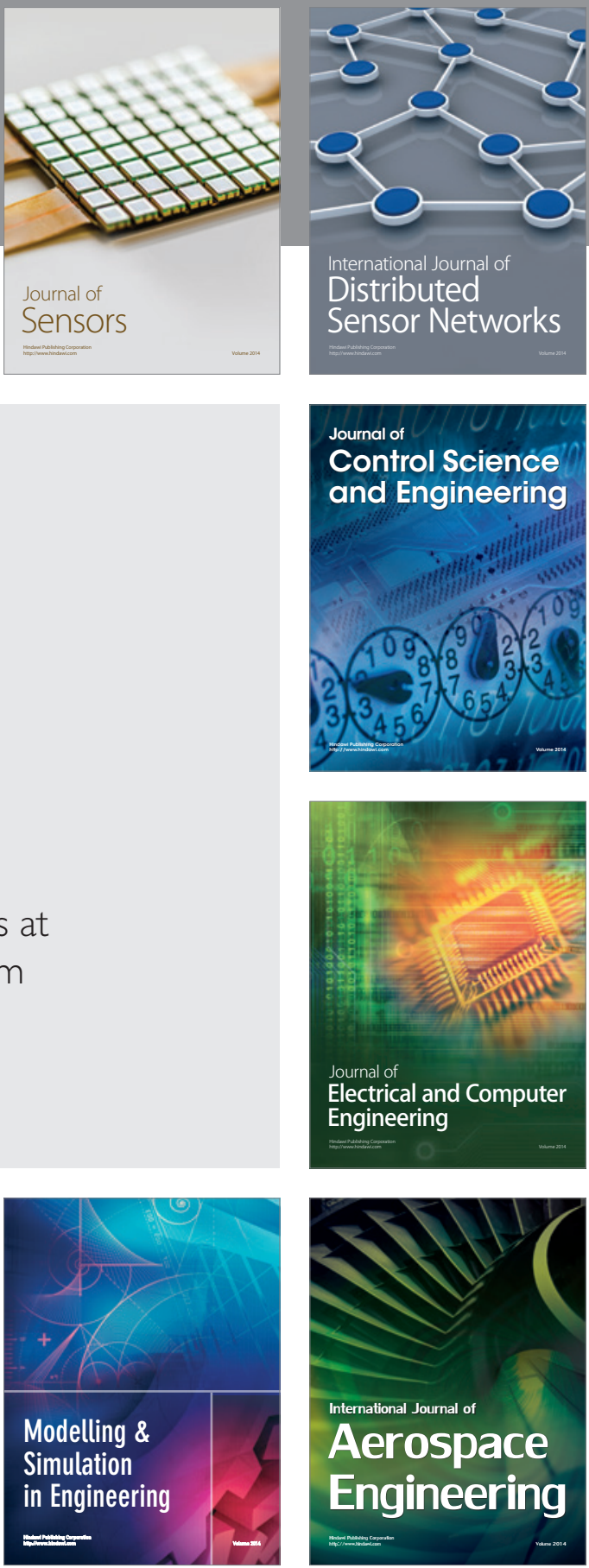

Journal of

Control Science

and Engineering
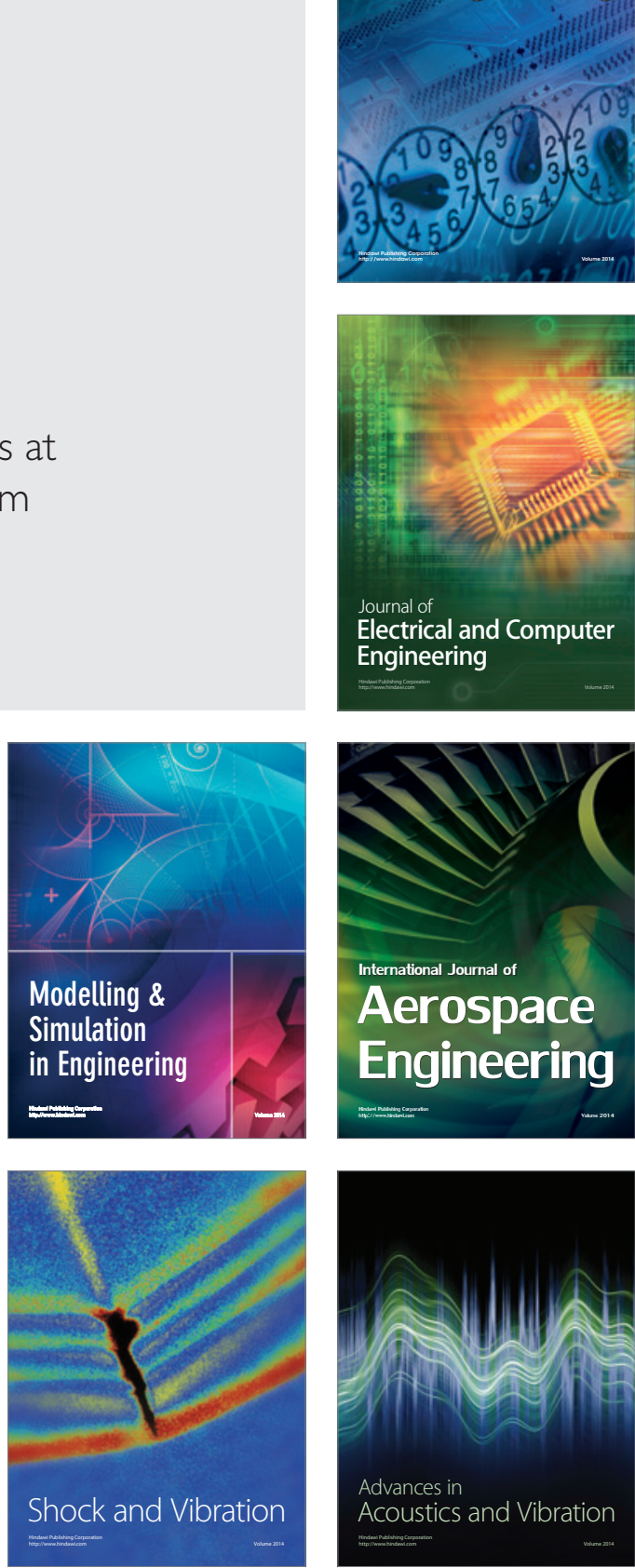